\title{
Pain in sciatica depresses lower limb nociceptive reflexes to sural nerve stimulation
}

\author{
JEAN-CLAUDE WILLER,* ANNA BARRANQUERO,$\dagger$ MARCEL-FRANCIS KAHN, $\dagger$ \\ DOMINIQUE SALLIÈRE
}

From the Laboratory of Clinical Neurophysiology, Faculty of Medicine Saint-Antoine, ${ }^{*}$ University of Paris VI, Clinique Rheumatologique, University of Paris, $\dagger$ and Laboratoire Ciba-Geigy, $\ddagger$ Paris, France

SUMMARY The inhibitory effects of acute pain produced by the Lasègue's manoeuvre on the lower limb nociceptive flexion reflexes induced by electrical sural nerve stimulation were explored in patients complaining of sciatica as a result of an identified unilateral disc protrusion. Lassègue's manoeuvre on the affected side produced a typical radicular pain and resulted in a powerful depression of nociceptive reflexes elicited either in the normal or in the affected lower limb. Simultaneously, patients reported relief of the electrically-induced pain. In contrast, painless Lasègue's manoeuvre on the normal side had no effect on these parameters.

The "pain inhibits pain" or counter-irritation phenomenon has been known for centuries and many popular methods of medicine included its therapeutic application for pain relief. ${ }^{1-5}$ However, since this phenomenon has not given rise to many clinical investigations involving humans' experimental pain, ${ }^{6-10}$ very little is known of its possible mechanisms. From animal studies, it has been proposed that inhibitory mechanisms occurring at the spinal level could be responsible for such counter-irritation phenomena. ${ }^{11}$ In support of this hypothesis, we have observed that heterotopic nociceptive stimuli produced by experimental pain (heat, cold, noxious pinch) reduced lower limb nociceptive reflexes and associated pain sensations in normal humans. ${ }^{12} \mathrm{We}$ now investigate whether similar findings are seen in patients complaining of acute or chronic pains.

The aim of the present work, carried out on patients with sciatica was to investigate the possible depressive effects of an acute neurological pain (Lasègue's sign) on lower limb nociceptive flexion reflexes to sural nerve stimulation. This procedure was chosen because these flexion reflexes were previously shown to be closely related to pain sensation, ${ }^{12-14}$ and because the Lasègue's sign (pain and limitation of

Address for reprint requests: Dr J-C Willer, Laboratory of Clinical Neurophysiology, Faculté de Médicine, Saint Antoine, 27 Rue Chaligny, 75571 Paris Cedex 12, France.

Received 14 January 1986 and in revised form 21 May 1986. Accepted 25 May 1986 movement during elevation of the leg when the knee is extended) is a useful test of this condition. The results demonstrated that pain induced by the Lasègue's manoeuvre resulted in depression of nociceptive reflexes elicited either in the normal or in the painful leg.

\section{Patients and methods}

The experiments were performed on eight inpatients with sciatica recently admitted for acute sciatica (see details in table). After being carefully briefed of the aim and procedure of this study, they gave their informed consent, according to the principles of the Helsinki declaration. All patients showed typical clinical features of a unilateral disc protrusion, confirmed by the myelography. They were selected on the basis that when lying in a resting position, they did not complain of spontaneous pain but all described a typical unilateral sciatica provoked by Lasègue's manoeuvre. The latter, also called the straight leg raising test, was performed as follows: with the patient in a supine position, the leg was slowly and passively elevated, keeping the knee fully extended. Normally, the leg can be elevated to $90^{\circ}$ without too much discomfort. Pain, particularly of the electric type that radiates into the feet, the back, or to the opposite side, indicates non-specific irritation of the sciatic nerve or root. For a given patient and before any treatment, the angle of Lasègue's sign was remarkably stable at one day intervals during successive examinations (see individual values in 
Table Summary of the main clinical features and the individual values of the threshold of the nociceptive reflex in the eight patients

\begin{tabular}{|c|c|c|c|c|c|c|c|c|c|}
\hline \multirow[t]{2}{*}{ Patients } & \multirow[t]{2}{*}{ Sex } & \multirow[t]{2}{*}{ Age (yr) } & \multirow[t]{2}{*}{ Disc protrusion } & \multirow[t]{2}{*}{$\begin{array}{l}\text { Slope of the } \\
\text { Lasegue's sign }\end{array}$} & \multirow[t]{2}{*}{ Jerks } & \multirow[t]{2}{*}{ Motor testing } & \multirow[t]{2}{*}{ Sensory testing } & \multicolumn{2}{|c|}{$\begin{array}{l}\text { Nociceptive reflex threshold }(m A) \text { in } \\
\text { relaxed position }\end{array}$} \\
\hline & & & & & & & & Normal side & Affected side \\
\hline $\begin{array}{l}1 \\
2 \\
3 \\
4 \\
5\end{array}$ & $\begin{array}{l}M \\
M \\
F \\
F \\
F\end{array}$ & $\begin{array}{l}37 \\
25 \\
47 \\
35 \\
27\end{array}$ & $\begin{array}{l}\text { Left L4-L5 } \\
\text { Left L5 } \\
\text { Left S1 } \\
\text { Right L5 } \\
\text { Right L5-S1 }\end{array}$ & $\begin{array}{l}27^{\circ} \\
38^{\circ} \\
53^{\circ} \\
20^{\circ} \\
27^{\circ}\end{array}$ & $\begin{array}{l}\text { Normal } \\
\text { Normal } \\
\text { Normal } \\
\text { Normal } \\
\text { Normal }\end{array}$ & $\begin{array}{l}\text { Normal } \\
\text { Normal } \\
\text { Normal } \\
\text { Normal } \\
\text { Normal }\end{array}$ & $\begin{array}{l}\text { Normal } \\
\text { Normal } \\
\text { Normal } \\
\text { Normal } \\
\text { Hypoesthesia } \\
\text { in L5 dermatome }\end{array}$ & $\begin{array}{r}9 \\
12 \\
10 \\
10 \\
10\end{array}$ & $\begin{array}{r}10 \\
11 \\
12 \\
9 \\
10\end{array}$ \\
\hline $\begin{array}{l}6 \\
7 \\
8\end{array}$ & $\begin{array}{l}\mathbf{M} \\
\mathbf{M} \\
\mathbf{M}\end{array}$ & $\begin{array}{l}41 \\
41 \\
63\end{array}$ & $\begin{array}{l}\text { Right L5 } \\
\text { Left L5-S1 } \\
\text { Right L4-L5 }\end{array}$ & $\begin{array}{l}50^{\circ} \\
45^{\circ} \\
35^{\circ}\end{array}$ & $\begin{array}{l}\text { Normal } \\
\text { Ankle jerk }=0 \\
\text { Normal }\end{array}$ & $\begin{array}{l}\text { Normal } \\
\text { Normal } \\
\text { Normal }\end{array}$ & $\begin{array}{l}\text { id } \\
\text { Normal } \\
\text { Normal }\end{array}$ & $\begin{array}{r}8 \\
10 \\
12\end{array}$ & $\begin{array}{r}9 \\
9 \\
10\end{array}$ \\
\hline
\end{tabular}

table). Thus, by using Lasègue's manoeuvre, it was easy to trigger a quantified neurological pain and to test its effects on the flexion reflexes investigation in this study. From a clinical point of view, all patients had normal motor and sensory function, except subject no 7 in whom the ankle jerk reflex was abolished on the affected side, and subjects 5 and 6 who exhibited cutaneous hypaesthesia in the L5 dermatome receptive field (see table). Patients were studied the day following their admission and before any treatment.

During the experimental sessions, the patients were lying in bed, in a painless position, ensuring a state of good muscular relaxation. The details of the method for stimulating the sural nerve and recording reflex activity from a knee flexor muscle have been described previously. ${ }^{12}{ }^{13}$ In brief, the sural nerve was stimulated at a rate of $0.25 \mathrm{~Hz}$ behind the lateral malleolus through a pair of surface electrodes $(2 \mathrm{~cm}$ apart) on the degreased skin. The electrical stimulus consisted of a volley of 6 rectangular pulses $(1 \mathrm{~ms}$ duration each) delivered over $20 \mathrm{~ms}$. Reflex responses were recorded from the ipsilateral biceps femoris muscle, using a pair of surface electrodes on the degreased skin overlying the muscle. These reflex responses were full-wave integrated (time window 100 $\mathrm{ms}, 80 \mathrm{~ms}$ after the stimulus onset).

The intensity of stimulation was varied randomly in order to determine the reflex threshold Tr). This latter was chosen for an intensity eliciting a probability of $80-90 \%$ of liminal responses. Thus, the stimulus intensity was adjusted at $1.2 \mathrm{Tr}$ and was kept constant at this level throughout each session lasting 50 minutes. This method was considered reliable since no clear sign of cumulative facilitatory or inhibitory effect to successive stimulations on the reflex activity was observed in previous studies using a similar procedure. ${ }^{14}$ Under these conditions, the general experimental procedure consisted in the study of the nociceptive reflex activity from both normal and painful sides during the four following situations: (1)
Lasègue's manoeuvre on the painful side, performed at the angle level giving rise to the Lasègue sign; (2) Lasègue's manoeuvre on the normal side (same angle level as in (1). Since these manoeuvres required a passive mobilisation of the lower limb by the experimenter the control sequences (one before and one after (1) and (2)) consisted in positioning the experimenter's hand so as to hold gently the concerned lower limb in a relaxed reclined position. These situations were selected for control data since some possible attentional processes can be induced by holding the leg during the Lasègue's manoeuvre and can modify the spinal reflex activity. ${ }^{15}$ Furthermore, since the Lasègue's manoeuvre-induced pain could result in voluntary or involuntary contraction of the muscles in the leg, we continuously monitored the EMG activity of the biceps femoris all through the sessions. All sequences which have shown a tonic or a phasic EMG activity resulting from these contractions have been excluded from this study. While the control sequences were always performed at the beginning and at the end of each exploration, situations 1 and 2 were randomly distributed on each leg and among the subjects. During each sequence lasting 3-4 minutes, a total of 15 successive reflex responses were averaged via an on-line computer program. The surface of the resulting averaged response was numerised and expressed as a percentage of the first control values (as $100 \%$ ). Numerical data were then statistically analysed by a study of the mean and variance. Paired $t$ test was used for studying the significance of variations.

\section{Results}

In the initial control sequence, the global mean value of the nociceptive reflex threshold (Tr) was of $10 \cdot 14$ $\pm 1.46 \mathrm{~mA}(\mathrm{~m} \pm \mathrm{SD})$ for the normal side and of $10.00 \pm 1.06 \mathrm{~mA}(\mathrm{~m} \pm \mathrm{SD})$ for the painful side (individual values are shown in table). There was no significant difference between these two values as 
Painful side stimulation

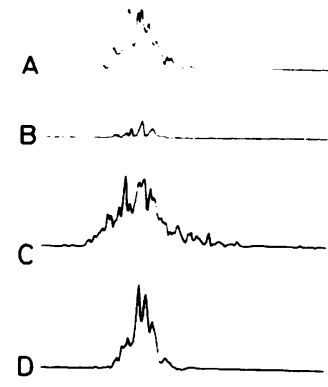

Fig 1

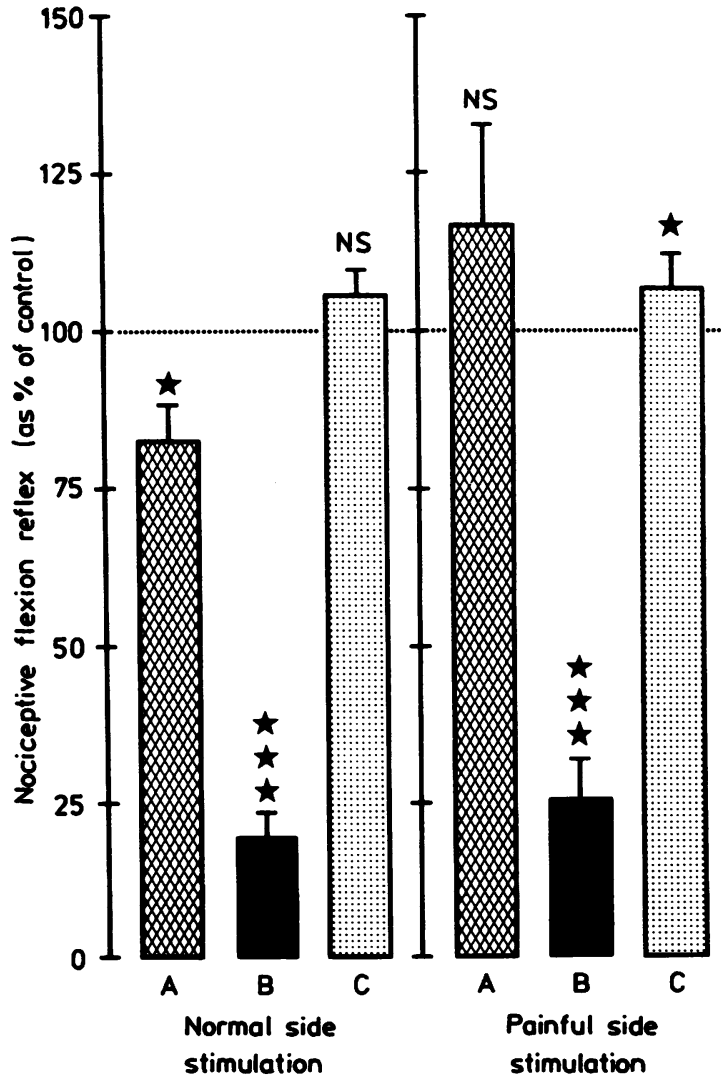

Normal side stimulation

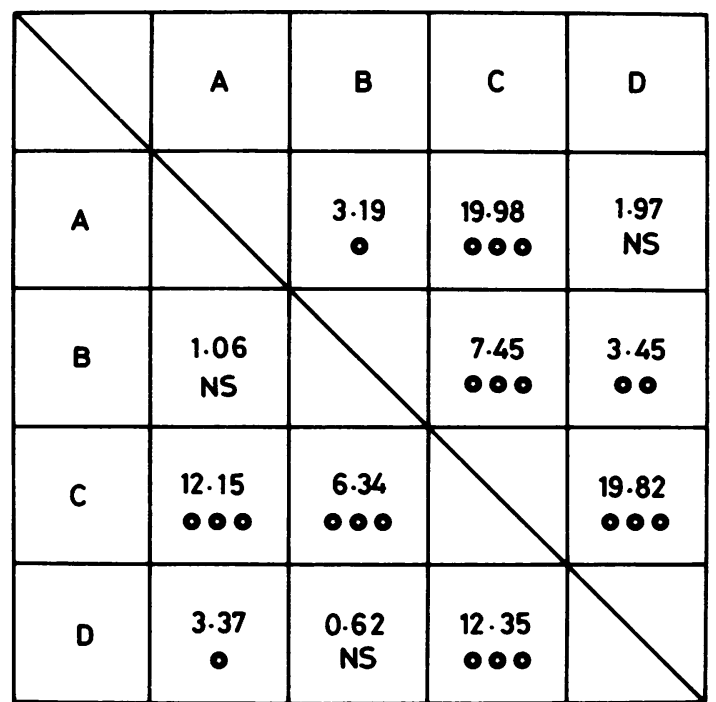

Painful side stimulation

Fig 3

Fig 1 Individual examples of nociceptive reflexes during $A$ $=$ control $1 B=$ Lasègue's manoeuvre on the affected side; $C$ : Lasègue's manoeuvre on the normal side; $D=$ control 2. Each trace corresponds to an averaging of 15 successive responses. Sural nerve stimulation and recordings from biceps femoris muscle are performed on the painful side (left) and on the normal side (right).

Fig 2 Pooled data showing the effect of the Lasègue's manoeuvre performed on the normal side $(A)$ or on the painful side $(B)$ on the nociceptive flexion reflex elicited by sural stimulation on the normal (left), or on the painful side (right). C (control 2) corresponds to a final control session. Values are expressed in terms of percentage of control I as $100 \%$ (details in the text).

Fig 3 Statistical analysis of data showing the significance of the variations of the nociceptive reflex in the four situations of sural nerve stimulation on the normal side (upper-right) and on the painful side (lower left). $A=$ Control 1; B = Lasègue's manoeuvre on the normal side: $C=$ Lasègue's manoeuvre on the painful side; $D=$ Control 2.

Fig 2 
revealed by the paired $t$ test $(t=0 \cdot 260 ; \mathrm{N}=8 ; \mathrm{NS})$. Thus, the stimulation used for this study, eliciting a supraliminal nociceptive reflex $(1.2 \mathrm{Tr}$ ) was very similar for both legs and for all subjects in a limited 10.8 $\pm 1.44 \mathrm{~mA}$ range. This kind of stimulation was described as a painful but tolerable sensation of needle prick surrounding the stimulating electrodes and projecting into the sural nerve receptive field. Furthermore, since the stimulation rate was sufficiently low, patients did not report any clearcut change in the quality and intensity of their sensations to successive stimulations along each session.

In these conditions, as shown in fig $1 \mathrm{~B}$ for one subject and fig 2 B for pooled data, Lasègue's manoeuvre performed on the painful side resulted in d large reduction of the nociceptive reflex either elicited on the normal side ( $80 \%$ depression) or on the painful side $(74 \%$ depression) respectively. Interestingly, during this situation, all subjects reported a significant relief of the electrically-induced pain which was described as masked by the sciatica pain provoked by the Lasègue's manoeuvre.

In contrast, as shown in fig $1 \mathrm{C}$ for one subject and fig $2 \mathrm{~A}$ for pooled data, a painless Lasègue's manoeuvre performed on the normal side produced a slight facilitatory effect on the nociceptive reflex elicited on the painful side $(+17 \%)$ and a slight inhibitory effect $(-17 \%)$ on the normal side evoked reflexes. A table of significance in the variations of the nociceptive reflex between all situations is shown in fig 3.

\section{Discussion}

The present study performed in patients with sciatica demonstrates that an acute neurological pain (dorsal root compression) triggered by the Lasègue's manoeuvre on the affected side can result in a profound depression of nociceptive reflexes to sural nerve stimulation elicited either on normal or on affected side. This effect was associated with a relief of the electrically induced-pain. These results confirm previous reports which have shown that the experimental pain thresholds can be increased by a conditioning painful stimulus applied to other areas of the body. ${ }^{69}$ Furthermore, our present data are also in agreement with one of our earlier reports ${ }^{12}$ which have shown that various modalities of experimentally-induced pains (heat, cold, pressure) applied to heterotopic body areas can depress simultaneously the nociceptive flexion reflex activity and the pain sensation to sural nerve stimulation. All these observations are probably relevant to counterirritation phenomena, as defined as the paradoxical pain relieving effect of pain elicited from other regions of the body. ${ }^{111617}$ Thus they provide experimental support for the use of intense cold for the treatment of clinical pain ${ }^{1819}$ such as ice massage of the hand for the relief of dental pain. ${ }^{5}$

As in our previous study, ${ }^{12}$ the observations reported here seem relevant to the mechanism described by Le Bars et al, ${ }^{1620}$ called "diffuse noxious inhibitory controls" (DNIC) described in the rat. These controls affect dorsal horn convergent neurons and some of the following points appear common with the inhibition of the nociceptive reflexes described above: (1) the responses of convergent neurons to electrical stimulation of their receptive field can be inhibited by noxious stimuli distant from the excitatory receptive field, (2) To be fully effective, the conditioning stimulus requires a temporal summation much greater (as was the 3-4 minutes Lasègue's manoeuvre duration) than the duration of the conditioned stimulus $(20 \mathrm{~ms}$ duration to sural nerve) (3) Similarly, the amount of nociceptive conditioning messages must be much greater than that of the conditioned afferent volley. That was probably the case in the present work since dorsal root compression produced by the Lasègue manoeuvre produced 4-5 minutes intense pain described as burning, aching, stabbing pain resulting from the activation of a large amount of $C$ and $A \delta$ fibres involved in pain transmission. In contrast, the intensity of sural nerve stimulation used here produced a short-lasting pricking pain which disappeared during the stimulation intervals. Previous studies $^{2122}$ have shown that this kind of stimulation activates predominantly the myelinated fibres $(A \alpha \beta$ and $A \delta$ ) of the peripheral nerves, (4) Finally, DNIC have also been shown to affect the polysynaptic reflex discharge evoked in the common peroneal nerve to sural nerve stimulation in the rat. ${ }^{23}$ This last observation, very similar to our data, indicates the ability of DNIC to modulate also nociceptive information transmitted through nociceptive reflex pathways. Thus, these parallels lead us to suggest that the inhibitory effects observed here in man and DNIC in the rat share common mechanisms. Since DNIC have been shown to be mediated via an ascendingdescending spino-bulbo-spinal complex loop, ${ }^{11}$ it would be crucial to know whether or not nociceptive conditioning stimulations are still able to depress the nociceptive reflexes in patients with identified brainstem or spinal lesions.

We thank Dr P Nathan for his helpful advice, Mrs M Gras and Miss $J$ Chandellier for assistance in the preparation of the manuscript.

\section{References}

1 Wand-Tetley JI. Historical methods of counterirritation. Ann Phys Med 1956;3:90-8. 
2 Melzack R. Prolonged pain relief by brief, intense transcutaneous somatic stimulation. Pain 1975;1:357-73.

3 Jeans ME. Relief of chronic pain by brief, intense transcutaneous electrical stimulation. A double-blind study. In: Advances in Pain Research and Therapy, vol. 3, Bonica JJ, Liebeskind JC, Albe-Fessard DG eds, New-York, Raven Press, 1979:601-6.

4 Melzack R, Guité S, Gonshor A. Relief of dental pain by ice massage of the hand. Can Med Assoc J 1980;122:189-91.

5 Melzack R, Jeans ME, Stratford JG, Monks RC. Ice massage and transcutaneous electrical stimulation: comparison of treatment for low-back pain. Pain 1980;9:209-17.

6 Duncker K. Some preliminary experiments on the mutual influence of pains. Psychol Forsch 1937;21:311-26.

7 Hardy JD, Goodell H, Wolff HG. The influence of skin temperature upon the pain threshold as evoked by thermal radiation. Science 1951;114:149-50.

8 Gammon GD, Starr I. Studies on the relief of pain by counterirritation. J Clin Invest 1941;20:13-20.

9 Parsons CM, Goetzl FR. Effect of induced pain on pain threshold. Proc Soc Exp Biol Med 1945;60:327-9.

10 Pertovaara A, Kemppainen P, Johansson G, Karnonen SL. Ischemic pain non segmentally produces a predominant reduction of pain and thermal sensitivity in man: a selective role for endogenous opioids. Brain Res 1982;251:83-92.

11 Le Bars D, Dickenson AH, Besson JM. Diffuse noxious inhibitory controls (DNIC). II. Lack of effect on nonconvergent neurones, supraspinal involvement and theoretical implications. Pain 1979;6:305-27.

12 Willer JC, Roby a, Le Bars D. Psychophysical and electrophysiological approaches to the pain-relieving effects of heterotopic nociceptive stimuli. Brain 1984;107:1095-112.
13 Willer JC. Comparative study of perceived pain and nociceptive flexion reflex in man. Pain 1977;3:69-80.

14 Willer JC. Studies on pain. Effects of morphine on a spinal nociceptive flexion reflex and related pain sensation in man. Brain Res 1985;331:105-14.

15 Willer JC, Boureau F, Albe-Fessard D. Supraspinal influences on nociceptive flexion reflex and pain sensation in man. Brain Res 1979;179:61-8.

16 Le Bars D, Dickenson AH, Besson JM. Diffuse noxious inhibitory controls (DNIC). I. Effects on dorsal horn convergent neurones in the rat. Pain 1979;6:283-304.

17 Le Bars D, Calvino B, Villanueva L, Cadden S. Physiological approaches to counterirritation phenomena. In: Stress-induced Analgesia. Tricklebank MD, Curzon G, Chichester: John Wiley, 1984:67-101.

18 Travell J. Ethyl chloride spray for painful muscle spasm. Arch Phys Med 1952;33:291-8.

19 Grant AE. Massage with ice (cryokinetics) in the treatment of painful conditions of the musculoskeletal system. Arch Phys Med Rehab 1964;45:233-8.

20 Le Bars D, Dickenson AH, Besson JM. The triggering of bulbo-spinal serotonergic inhibitory controls by noxious peripheral inputs. In: Brain Stem Control of Spinal Mechanisms. Sjolune B, Bjorklund A, eds, Amsterdam, Elsevier Biomedical Press, 1982:381-410.

21 Willer JC, Boureau F, Albe-Fessard D. Role of large diameter cutaneous afferents in transmission of nociceptive messages: electrophysiological study in man. Brain Res 1978;152:358-64.

22 Willer JC, Boureau F, Albe-Fessard D. Human nociceptive reactions: effects of spatial summation of afferent input from relatively large diameter fibers. Brain Res 1980;201:465-70.

23 Schouenborg J, Dickenson AH. The effects of a distant noxious stimulation on $\mathbf{A}$ and $\mathbf{C}$ fibre evoked flexion reflexes and neuronal activity in dorsal horn of the rat. Brain Res 1985;328:23-32. 